\title{
SPATIAL PREDICTION OF AIR TEMPERATURE IN EAST CENTRAL ANATOLIA OF TURKEY
}

\author{
B.C. Bilgili ${ }^{1}$, S. Erşahin ${ }^{2}$, M. Özyavuz ${ }^{3}$ \\ ${ }^{1}$ Çankırı Karatekin University, Faculty of Forestry, Department of Landscape Architecture, 18200, Çankır1/ TURKEY. \\ bcbilgili@karatekin.edu.tr \\ ${ }^{2}$ Çankırı Karatekin University, Faculty of Forestry, Department of Forest Engineering, 18200, Çankırı/ TURKEY. \\ acapsu@gmail.com \\ ${ }^{3}$ Namık Kemal University, Department of Landscape Architecture,59030, Tekirdağ/ TURKEY. \\ mozyavuz@gmail.com
}

KEY WORDS: Ordinary Kriging, Ordinary Cokriging, Malatya, Apricot, Model Efficiency

\begin{abstract}
:
Air temperature is an essential component of the factors used in landscape planning. At similar topographic conditions, vegetation may show considerable differences depending on air temperature and precipitation. In large areas, measuring temperature is a cost and time-consuming work. Therefore, prediction of climate variables at unmeasured sites at an acceptable accuracy is very important in regional resource planning. In addition, use a more proper prediction method is crucial since many different prediction techniques yield different performance in different landscape and geographical conditions. We compared inverse distance weighted (IDW), ordinary kriging $(\mathrm{OK})$, and ordinary cokriging $(\mathrm{OCK})$ to predict air temperature at unmeasured sites in Malatya region (East Central Anatolia) of Turkey. Malatya region is the most important apricot production area of Turkey and air temperature is the most important factor determining the apricot growing zones in this region. We used mean monthly temperatures from 1975 to 2010 measured at 28 sites in the study area and predicted temperature with IDW, OC, and OCK techniques, mapped temperature in the region, and tested the reliability of these maps. The OCK with elevation as an auxiliary variable occurred the best procedure to predict temperature against the criteria of model efficiency and relative root mean squared error.
\end{abstract}

\section{INTRODUCTION}

Air temperature is an important factor determining landscape characteristics. (Apaydin et al., 2011) as it influences many biotic processes such as phenology, carbon fixation, evapotranspiration and soil-water-plant relations. In planning landscapes resilient to climate changes, distribution of air temperature over landscape should be considered. Air temperature not only affects vegetation characteristics above soil surface but also vertical and horizontal distribution of soil temperature. Rates of many soil processes, which have strong control on plan growth are directly and indirectly related to soil temperature (Campbell and Norman, 1998). Geology and geomorphology, hydrology, landcover and atmospheric circulation patterns may also have a strong influence on spatial distribution of air temperature (Aznar et al., 2013).

Different landscape vegetation covers may form at similar topographic conditions, due to difference in air temperature. Interactions between air temperature and plant cover may be different on a same topography due to local differences in slope steepness and aspect and soil and canopy conditions (Campbell and Norman, 1998). Air temperature has a strong control on soil moisture regime, determining the vegetation type, density, and litter composition (Zhao et al., 2005; Attorre et al., 2007). Therefore, air temperature is one of the principal factors mediating plant and animal adaptation on a landscape.

In the Malatya region, there are two principal obscures in building maps of air temperature. First, the area is highly mountainous. As stated by (Moral, 2010) it is highly difficult to predict climate variables in a mountainous region due to complex topography. Second, the meteorical measurement stations are scarce and distributed non-uniformly, and this limits predictions in unmeasured sites with an acceptable accuracy. This problem may be overcome; using proper prediction techniques (VicenteSerrano et al., 2003).

Many prediction techniques are used in environmental studies. Li and Heap (2011) reviewed 53 studies and compared performance of 85 techniques/sub techniques widely used in environmental studies. They reported that inverse distance weighting (IDW), ordinary Kriging $(\mathrm{OK})$ and ordinary cokriging (OCK) were the most frequently used techniques in environmental studies. Li and Heap (2011) also stressed that many times, performance of a technique is controlled by the nature of data (sampling density and scheme), type of variable, and most importantly variation of the data.

Different prediction techniques may perform differently in different landscapes Hudson and Wackernagel, 1994). Many studies showed that OK or OCK outperformed the deterministic techniques such as IDW and polygonal prediction techniques (Moral, 2010). Chuanyan et al. (2005) evaluated prediction techniques of OK, Splines, and IDW, and they concluded that all three methods yielded greater prediction error than linear regression, which accounted for terrain attributes. However, Didari et al., (2012) used OK, regression kriging (RK), universal kriging (UK), and modified inverse distance weighting (MIDW) to predict frost date at unmeasured sites. They found that the MIDW prediction outperformed other techniques they used.

Techniques ignoring terrain attributes such as slope steepness, slope aspect, and distance are generally outperformed by their counterparts in predicting temperature in mountainous regions. For example, studies (Diadato, 2005; Moral, 2010) showed that OCK predicted precipitation better when altitude was used as auxiliary variable of precipitation. Moral (2010) compared 
performance of OK, simple kriging (SK), universal kriging (UK), and OCK in predicting monthly and annual precipitation in in 41 $600 \mathrm{~km}^{2}$ area in southwest of Spain. Their results showed that multivariate geostatistical techniques generally outperformed the univariate geostatistical techniques of OK, UK, and SK.

Many different crops are grown in Malatya region, including apricot, which is the principal crop in the region. Malatya is one of the most important agro-ecological apricot producing region in the world, producing $11 \%$ of world's and 70\% Turkey's total (Ünal,2010). In Malatya, determination of agro-climatic zones for apricot production planning is crucial and requires use of air temperature, which is one of the most important climate variable affecting both quality and quantity of the production. Spatial and temporal variation of air temperature are important in determining apricot growing zones (Güler and Kara, 2012). Knowing spatial structure of air temperature will help determine correlation zones of surface temperature, which can be considered homogenous (statistically) in production planning.

This study aimed to assess performance of most widely used three techniques to predict air temperature in Malatya region, located in east of Central Anatolia of Turkey. The results showed that OCK outperformed IDW and OK according to evaluation criteria of model performance and relative root mean squared error. should be single-spaced, unless otherwise stated. Left and right justified typing is preferred.

\section{REVIEW OF THE STATISTICAL METHODS}

\subsection{Length and Font}

Spatial aucorrelation (or simply correlation) of a variable is widely described by semivariogram and cross-semivariogram functions. Equation (1) has been used widely to predict spatial correlation (Yates and Warrick, 1987).

$$
\gamma_{\mathrm{ij}}(h)=\sum^{n(h)}\left\{\left[z_{i}\left(x_{k}+h\right)-z_{i}(x)\right]\left[z_{j}\left(x_{k}+h\right)-z_{j}(x)\right]\right\} / 2 n(h){ }^{v} \sum_{i=1} w_{i} \cdot v
$$

Where $\gamma_{i j}$ is the semivariance (when $i=j$ ) with respect to variable $z_{i}, h$ is the separation distance, $n(h)$ is the number of pairs of $z_{i}\left(x_{k}\right)$ in an given lagged distance interval of $(h+d h)$. When $\mathrm{i} \neq$ $\mathrm{j}, \gamma_{i j}$ is the cross-semivariogram (Yates and Warrick, 1987).

Semivariograms and cross-semivariograms were fitted using the spherical (Eq. (2)) and Gaussian (Eq. 3) models:

$$
\gamma_{i j}=\left(\begin{array}{ll}
C_{0}+C\left[1.5 \frac{h}{a}-0.5\left(\frac{h}{3}\right)^{3}\right] & \text { if } h<a \\
C_{0}+C & \text { if } h \geq a
\end{array}\right)
$$

$$
\gamma_{i j}=C_{0}+C\left[1-\exp \left(-\frac{h^{2}}{a^{2}}\right]\right.
$$

Where $C_{0}$ is the nugget variance, $C$ is the sill, $a$ is the geostatistical range, and $h$ is the lagged distance. Spatial distribution of air temperature along with elevation was predicted, applying the best-fit mathematical functions of experimental semivariograms and cross-semivariograms.

\subsection{Spatial Prediction}

Where $v$ is predicted value of variable $v$ at an unmeasured site and $w$ is the weight attained to the neighboring measured values of $v$. Detailed information on kriging can be found in Isaaks and Srivastava (1989).

\subsubsection{Inverse distance weighted (IDW)}

The inverse distance weighted (IDW) method estimates the values of subject variable in unmeasured points using a linear combination of the variable's values at measured points weighted by an inverse function of the distance from the point of interest to the measured points. This technique assumes that measured values closer to an unmeasured point are more similar to it than those are further away in their values ( $\mathrm{Li}$ and Heap 2008). The IDW uses Eq. (4) in making prediction:

$$
\lambda_{i}=\frac{1 / d_{i}{ }^{p}}{\sum_{i=1}^{n} 1 / d_{i}{ }^{p}}
$$
predicted, and $p$ is the power attained to inverse distances between neighboring data points and point where varible $x$ is predicted. The exponent $p$ an important factor affecting the calculations.

\subsubsection{Kriging}

Ordinary Kriging (OK) and ordinary cokriging (OCK) methods use spatial structure of data to make predictions in unvisited sites. Krige (1951) applied geostatistics in mining first time, so the method was named kriging in his honor (Malvic and Durekovic, 2003). "The basis of kriging is the semivariogram, which is a representation of the spatial and differences in data between some or all possible 'pairs' of measured points, as a function of distance between points" (Attore et al., 2007). At an unvisited site, value of a subjected variable is predicted by Eq. (5) (Isaaks and Srivastava, 1989).

$$
\hat{v}=\sum_{i=1}^{n} w_{i} \cdot v
$$

\subsubsection{Cokriging}

The ordinary cokriging (OCK) procedure uses information on autocorrelation of a primary variable (a difficult to measure variable) and on cross-correlation between primary and auxiliary variable (a relatively easy to measure variable). The procedure OCK minimizes the estimation variance using both autocorrelation of primary variable $(u)$ and cross-correlation between $u$ and secondary variable $(v)$ (Isaaks and Srivastava, 1989). Similar to that in kriging, value for a variable at an unvisited site is predicted by Eq. (6) (Isaaks and Srivastava, 1989).

$$
\hat{u}(x)=\sum_{i=1}^{n} a_{i} \cdot u_{i}+\sum_{j=1}^{m} b_{j} \cdot v_{j}
$$

(6)

Where, $\hat{u}(x)$ is the prediction of variable $u$ at the location $x$, a is the weight given to the measured neighboring values of variable $u$ (primary variable), $b$ is the weight given to measured neighboring values of variable $v$ (auxiliary variable). To exploit 
spatial correlation between primary and secondary (auxiliary) variable in predicting the primary variable, a reasonable spatial correlation between two variables should be sought. A strong correlation between two variables at $\mathrm{h}=0$ may not guarantee an adequate spatial correlation between two variables. A correlogram analysis prior to cokriging may be a good start to examine spatial aucorrelation between primary and secondary variables.

\section{MATERIALS AND METHODS}

Study area (Malaya and its ambiance) is located in east-central Anatolia of Turkey (Figure 1). Malatya and its surrounding region approximately $\left(129600 \mathrm{~km}^{2}\right)$ is located in $3554^{\prime}$ and 39 $03^{\prime}$ northern latitudes and 38 45' and 39 08' eastern longitudes (Anonymous, 2013a). The elevation in the region ranges from $540 \mathrm{~m}$ to $2600 \mathrm{~m}$. There are 28 climate stations operated by State Meteorology General Directorate in the study area. The average lowest mean temperature occurs in January $\left(-6.3^{\circ} \mathrm{C}\right)$ in Sivas and highest in July $\left(34.1{ }^{\circ} \mathrm{C}\right)$ in Şanliurfa climate station (Anonymous, 2013b).

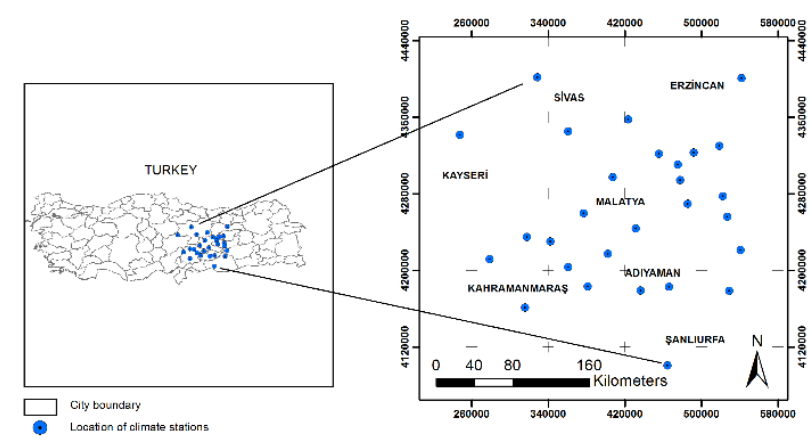

Figure 1. Location of study area and climate stations in the study area.

\subsection{Methods}

Descriptive statistics (mean, minimum, maximum, coefficient of variation, skewness, and kurtosis) for mean monthly air temperatures (MMAT) were calculated for 28 climate stations. Semivariogram models for MMATs were best-fitted using GS+ Gamma Design Software (Robertson, 1998). Air temperature was predicted at unmeasured sites by inverse distance weighted (IDW), ordinary kriging (OK), and ordinary cokriging (OCK). The prediction performance of these three methods was evaluated against model efficiency and relative root mean squared error. In OCK estimation, 192 values of elevation from see level (auxiliary variable) was used along with 28 mean monthly air temperature (primary variable) values (Figure 2). Spatial pattern of predicted air temperatures (MMAT) were mapped with Arcview 10.

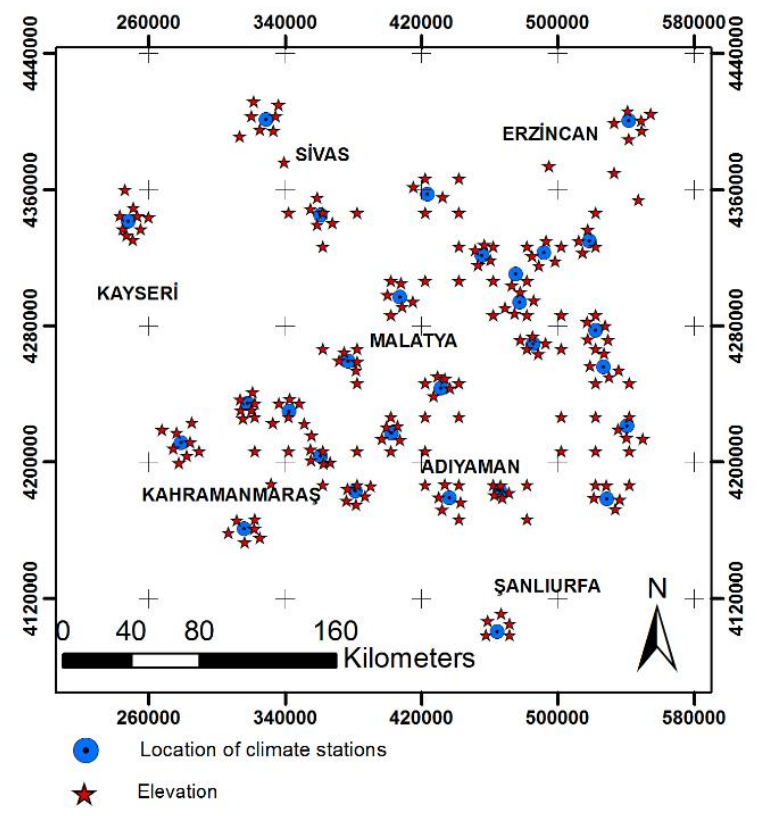

Figure 2. Spatial orientation of primary (mean monthly temperature) and auxiliary (elevation) values used in the ordinary cokriging prediction.

\subsection{Results}

Descriptive statistics of monthly temperatures measured from 1975 to 2010 are given in Table 1. Air temperature is extremely variable in January and February and moderately variable in the summer months (Table 1). Distribution of temperature values is slightly right skewed for all the cases; however, since the coefficient of skewness is below 0.50 , the distribution is deemed normal as suggested by (Webster, 2001). In addition, the distribution of mean monthly temperature values is slightly negatively kurtotic (Table 1).

Data variation is an important factor affecting performance of prediction techniques. $\mathrm{Li}$ and Heap (2011) showed that data variation has a stronger influence on model performance compared to data resolution, and that irregularly spaced sampling may increase the accuracy of the prediction. Greater CV-values corresponding to winter months are attributed the greater differences in air temperatures measured in mountainous and flat landscapes in winter compared to those in summer months. It is possible that cold air circulations can influence the mountainous northern region of the study area more than the flatter southern region, and this would result in greater difference between temperatures measured at meteorological stations located in mountainous region. Greater skewness values obtained for the winter months show that some high outliers measured in some locations. These outliers would also inflate the CV-values obtained for the region.

\section{Spatial predictions}

Inverse distance weighted (IDW), ordinary kriging (OK), and ordinary cokriging (OCK) are most frequently used techniques in environmental studies for the purpose of spatial interpolation of data (Li and Heap, 2011). We compared these three techniques for interpolating air temperature in a approximately (129 600) $\mathrm{km}^{2}$ landscape with highly different topography in 


\begin{tabular}{lcccccccccccc}
\hline & Jan. & Feb. & Mar. & Apr. & May & Jun. & Jul. & Aug. & Sep. & Oct. & Nov. & Dec. \\
\hline Mean & -0.50 & 0.80 & 5.67 & 11.58 & 16.47 & 21.78 & 25.83 & 25.53 & 20.68 & 14.20 & 6.92 & 1.70 \\
Min & -6.30 & -5.10 & 0.10 & 6.60 & 11.10 & 15.20 & 18.90 & 18.90 & 13.90 & 8.10 & 1.40 & -3.60 \\
Max & 4.80 & 6.20 & 10.50 & 15.30 & 20.60 & 27.40 & 31.50 & 30.80 & 25.50 & 19.20 & 11.80 & 6.60 \\
\#CV\% & 597.60 & 355.79 & 45.86 & 19.34 & 15.72 & 14.73 & 13.33 & 13.02 & 15.52 & 21.22 & 38.93 & 158.66 \\
Skewness & 0.41 & 0.34 & 0.14 & 0.00 & 0.12 & 0.09 & -0.02 & -0.07 & -0.11 & 0.13 & 0.27 & 0.46 \\
Kurtosis & -0.66 & -0.52 & -0.39 & -0.54 & -0.78 & -0.75 & -0.79 & -0.86 & -0.85 & -0.80 & -0.65 & -0.66 \\
\#SD & 2.97 & 2.86 & 2.60 & 2.24 & 2.59 & 3.21 & 3.44 & 3.32 & 3.21 & 3.01 & 2.69 & 2.70 \\
\hline
\end{tabular}

${ }^{\#} \mathrm{CV}$ : Coefficient of variation, SD: Standard deviation

Table 1. Descriptive statistics of mean monthly temperatures measured from 1975 to 2010

\section{Spatial predictions}

Inverse distance weighted (IDW), ordinary kriging (OK), and ordinary cokriging (OCK) are most frequently used techniques in environmental studies for the purpose of spatial interpolation of data ( $\mathrm{Li}$ and Heap, 2011). We compared these three techniques for interpolating air temperature in a approximately (129 600) $\mathrm{km}^{2}$ landscape with highly different topography in east central Anatolia. We compared models with their performance by relative root mean squared error (RRMSE) and model efficiency $(E F)$ introduced by $\mathrm{Li}$ and Heap (2011). The RRMSE has the form (Li and Heap, 2011):

$$
R R M S E=\frac{1}{n} \sum_{i=1}^{n}\left(\left(\frac{\left[p_{i}-o_{i}\right]}{o_{i}}\right)^{2}\right)^{1 / 2}
$$

\section{(7)}

Where $p$ is the predicted and $o$ is the observed value of subject attribute. Eq. (7) cannot yield reasonable results when an $o_{i}$ is zero. Therefore, we discarded one of our data values and calculated RRMSE with 27 of 28 data values.

Model efficiency $(E F)$ can be calculated by Eq. (8) (Li and Heap, 2011).

$$
E F=1-\frac{\sum_{i=1}^{n}\left(p_{i}-o_{i}\right)^{2}}{\sum_{i=1}^{n}\left(\bar{o}-o_{i}\right)^{2}}
$$

(8)
Where $\bar{o}$ is the mean of observed values.

Of the three methods, IDW performed the worst and OCK performed the best. The calculated $E F$ values for IDW were as low as 0.50 (Table 2) for January and February, while $E F$ values of 0.78 and 0.80 were calculated for OCK-predicted values for the same months. The OCK did not perform well for these two months. Values of $E F$ and CV (Table 2) correlated negatively, suggesting that the criterion $E F$ was sensitive to data variation, which generally highly affect prediction quality ( $\mathrm{Li}$ and Heap, 2011). Compared to $E F, R R M S E$ calculated from OCK, OK, and IDW behaved somehow differently. Greatest $R R M S E$ value (the worst model performance) occurred for March, while the lowest $E F$ (the worst model performance) occurred for February for all three techniques. We suggest that $E F$ should be given besides RRMSE in evaluating model performance. We compared root mean squared error (RMSE) and cross-validation correlation coefficient (r) to $E F$ and RRMSE to evaluate model performance (data are not given). Both $E F$ and RRMESE appeared to be more successful in evaluating model performance. We attributed this greater performance of RRMSE and EF that these techniques normalize the error values to data values and use this normalized error values in evaluation model performance. Standard deviation (SD) is a measure of data dispersion or variation about the mean and it is frequently used to evaluate similarity of measured values to predicted ones (Isaaks and Srivastava, 1989). Compared to OK- and IDW-predicted values, OCK- predicted mean monthly temperatures were more similar to measured ones as their SDs were closer to those of measured values (Table 2). We attributed greater success of OCK to its use of spatial correlation information between temperature and elevation (Table 2). 
EF: Model efficiency, RRMSE: Relative root mean squared error, \#CV: Coefficient of variation, r: correlation coefficient between mean monthly temperature and elevation from the see level.

\begin{tabular}{|c|c|c|c|c|c|c|c|c|c|c|c|c|}
\hline & \multicolumn{2}{|c|}{ Measured } & \multicolumn{4}{|c|}{ OCK } & \multicolumn{3}{|c|}{ IDW } & \multicolumn{3}{|c|}{ OK } \\
\hline & Mean & ${ }^{\#} \mathrm{CV} \%$ & ${ }^{*} \mathrm{r}$ & Mean & $\mathrm{EF}$ & RRMSE & Mean & $\mathrm{EF}$ & RRMSE & Mean & $\mathrm{EF}$ & RRMSE \\
\hline Jan. & -0.5 & 597.60 & 0.949 & -0.25 & 0.778 & 227.88 & -0.48 & 0.500 & 194.27 & -0.6 & 0.582 & 355.89 \\
\hline Feb. & 0.8 & 355.79 & 0.951 & 1.04 & 0.803 & 173.60 & 0.83 & 0.551 & 290.27 & 0.68 & 0.591 & 353.52 \\
\hline Mar. & 5.67 & 45.86 & 0.961 & 5.87 & 0.988 & 645.04 & 5.69 & 0.968 & 847.39 & 5.58 & 0.969 & 679.40 \\
\hline Apr. & 11.58 & 19.34 & 0.963 & 11.77 & 0.998 & 12.73 & 11.62 & 0.994 & 19.54 & 11.5 & 0.993 & 19.27 \\
\hline May & 16.47 & 15.72 & 0.951 & 16.69 & 0.999 & 8.95 & 16.54 & 0.996 & 13.68 & 16.38 & 0.996 & 13.31 \\
\hline Jun. & 21.78 & 14.73 & 0.927 & 22.11 & 0.999 & 7.43 & 21.92 & 0.997 & 11.34 & 21.68 & 0.998 & 10.38 \\
\hline Jul. & 25.83 & 13.33 & 0.897 & 26.22 & 0.999 & 6.99 & 26.06 & 0.998 & 10.08 & 25.5 & 0.998 & 8.77 \\
\hline Aug. & 25.53 & 13.02 & 0.895 & 25.92 & 0.999 & 7.52 & 25.75 & 0.998 & 10.23 & 25.5 & 0.998 & 9.21 \\
\hline Sep. & 20.68 & 15.52 & 0.901 & 21.01 & 0.998 & 10.63 & 20.85 & 0.997 & 13.40 & 20.54 & 0.997 & 12.62 \\
\hline Oct. & 14.2 & 21.22 & 0.916 & 14.5 & 0.996 & 15.55 & 14.3 & 0.994 & 19.29 & 14.1 & 0.995 & 17.53 \\
\hline Nov. & 6.92 & 38.93 & 0.925 & 7.15 & 0.988 & 54.10 & 6.95 & 0.979 & 66.28 & 6.84 & 0.983 & 56.07 \\
\hline Dec. & 1.7 & 158.66 & 0.952 & 1.91 & 0.906 & 300.31 & 1.7 & 0.776 & 556.44 & 1.61 & 0.812 & 580.88 \\
\hline
\end{tabular}

Table 2. Measured and predicted mean monthly air temperatures in the study area

This cross-correlation information, as reported by Moral (2010) and Chuanyan et al. (2005), increased the accuracy of air temperature predictions in unvisited sites. In addition, RRMSE values showed that the all three models performed well for predicting surface temperatures in the summer months compared to winter months. We attributed this better success of these methods to less variation of data in summer months (Table 1) as suggested by Li and Heap (2011). Moral (2010) reported that OK and OCK predicted better than IDW and other deterministic techniques such as polygonal method and regression kriging and that when topography was used as a secondary variable, the OCK outperformed the univariate geostatistical techniques of regression kriging, simple kriging, and universal kriging in a 41,000-ha area in southwest Spain. Since univariate geostatistical techniques ignore terrain attributes, their performance remain relatively lower than those of multivariate geostatistical techniques such as OCK (Chuanyan et al., 2005).

In general, temperature decreases $6.4{ }^{\circ} \mathrm{C}$ per $1000 \mathrm{~m}$ (Apaydin et al., 2011). Thus, in general, models that account for terrain attributes in temperature predictions outperform those not do. Apaydin et al. (2011) compared OK and OCK to predict mean monthly temperatures on a varying topography in Central Anatolia, Turkey. They reported that OCK predicted better than OK since the former accounts for elevation as a second variable. However, it is difficult to generalize the models by their performance since the model performance is highly casesensitive. Majority of the studies showed better results when OK or OCK are used compared to empirical multiple regression modeling (Moral, 2010), while in some other cases nongeostatistical techniques performed better. For example, Didari and Parsa (2012) used OK, OCK, regression kriging (RK), universal kriging (UK) and modified IDW (MIDW) to predict frost date. They reported that MIDW predictions were generally more reasonable than any of the other techniques they used.

The use of OCK requires that a reasonably strong correlation occur between primary and secondary variables and secondary variable should be oversampled relative to primary variable (Isaakas and Srivastava, 1989). In our study, a strong correlation coefficient (r) occurred between air temperature values and altitude for all the months (Table 2), suggesting that this strong $r$ resulted in OCK to outperform OK and IDW in predicting monthly surface temperatures. The model performance depends on the topography as well as the correlation degree between topographic variables and surface temperature. For example, Zhao et al. (2005) reported that geostatistical methods OK and splines yielded smaller prediction errors than linear regression of temperature. However, Chuanyan et al. (2005) evaluated OK and splines and they concluded that, in general, OK and spline resulted in greater prediction errors compared to linear regression, which accounts for terrain attributes. On the other hand, Yang et al. (2004) recommended OCK to predict temperature in the case of rough terrains and varying elevations. Spatial pattern of monthly average surface temperatures are given in (Figure 3) where greater temperature values are associated to flatter topographies. In general, mean monthly air temperature gradually increased from northwest to southeast and similar pattern occurred for all 12 months.

The major advantage of kriging over other nongeostatistical methods is its measuring prediction error for each predicted values. A greater prediction error indicates poorer prediction. Prediction error map for two extreme months January (greatest $\mathrm{CV}$ ) and August ( lowest CV) were presented in (Figure 4) for comparison. Our results showed that OCK predicted better in northwestern part of the study area and that it predicted worse in southeastern corner and an isolated area in the south (Figure 4). Contrary to many cited results, OCK predicted well in the mountainous localities than flatter topographies, which we attributed that more strong correlation occurred between temperature and altitudes on mountainous topographies and this helped OCK better predict surface temperatures on these topographies. Similar results reported by Yang et al. (2004). A similar spatial prediction error pattern occurred for all 12 months (data are not given). The maps in (Figure 4) should be interpreted 
carefully since prediction error is relative to monthly averages of surface temperature.

\section{CONCLUSIONS}

We predicted mean monthly air temperatures by ordinary kriging (OK), ordinary cokriging (OCK, and inverse distance weighted (IDW). The OCK outperformed IDW and OCK. Data variation affected model performance for all three models. All three models predicted well in summer months with relatively less data variations than winter months when data variation was greatest. However, IDW and OK did not predict as well as OCK in winter
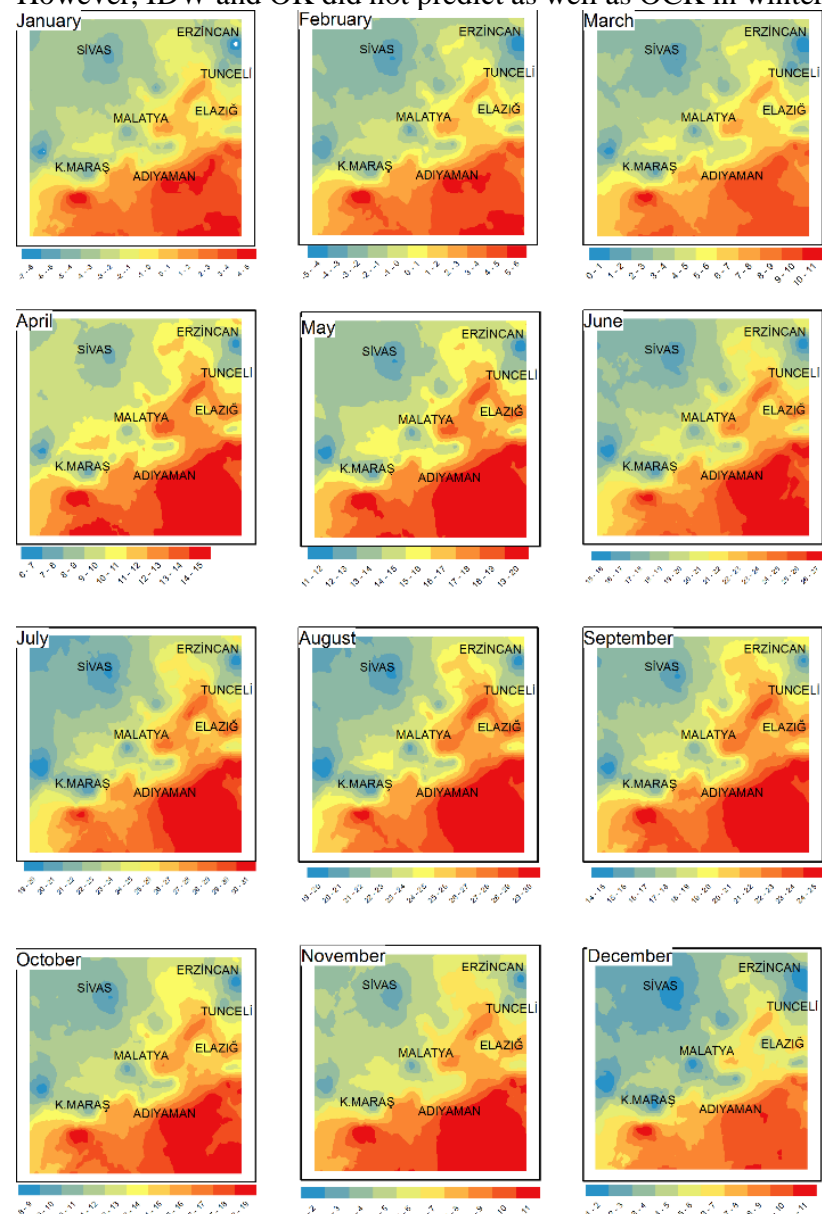

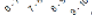

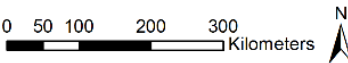

Figure 3. Mean monthly air temperature predict with OCK.

\section{REFERENCES}

Anonymous, 2013a. Geographical location of Malatya. T.C. Malatya Valiliği, Malatya

Anonymous, 2013b. Official statistics (statistical data of provinces and districts). Turkish State Meteorological Service, Ankara

Apaydin H, Anli AS, and Ozturk F. 2011. Evaluation of topographical and geographical effects on some climatic parameters in the Central Anatolia Region of Turkey. International Journal of Climatology 31(9): 1264-1279. DOI: $10.1002 /$ joc. 2154 months. The OCK performed well in predicting mean monthly temperature in mountainous region of the study area. Very high correlation occurred between monthly air temperatures and altitude as shown by calculated correlation coefficients. Therefore, we attributed this high performance of OCK to its use of spatial autocorrelation between altitude and air temperature. The OCK performed well on the mountainous landscapes due to high correlation coefficient occurred between altitude and air temperature. We suggest that OCK may be preferred over other prediction techniques if a strong correlation exists between the subject variable and topographic variables.

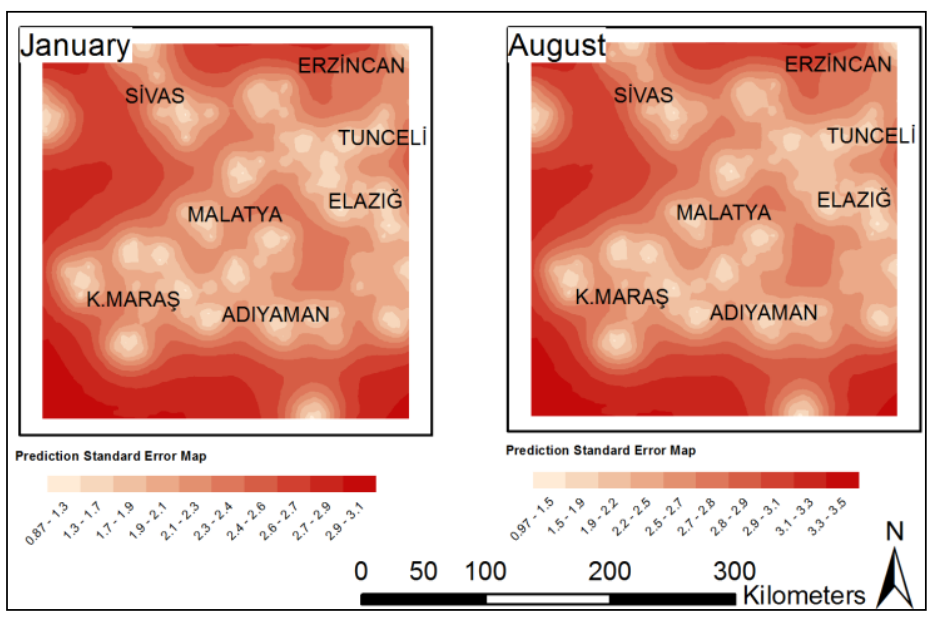

Figure 4. Maps of prediction error map for January (with greatest CV) and August (with lowest CV)

Attorre F, Alfo M, De Sanctis M, Francesconi F, Bruno F. 2007. Comparison of interpolation methods for mapping climatic and bioclimatic variables at regional scale. International Journal of Climatology 27(13): 1825-1843. DOI: 10.1002/joc.1495

Aznar JC, Gloaguen E, Tapsoba D, Hachem S, Caya D, Begin Y. 2013. Interpolation of monthly mean temperatures using cokriging in spherical coordinates. International Journal of Climatology 33(3): 758-769. DOI: 10.1002/joc.3468

Campbell GS, Norman JM. 1998. An introduction to environmental biophysics. Springer: New York

Chuanyana Z, Zhongrenb N, Guodong C. 2005. Methods for modelling of temporal and spatial distribution of air temperature at landscape scale in the southern Qilian mountains, China. $\begin{array}{lll}\text { Ecological } & \text { Modelling } & \text { 189: 209-220. }\end{array}$ DOI:10.1016/j.ecolmodel.2005.03.016 
Didari S, Zand-Parsa S, Sepaskhah AR, Kamgar-Haghighi AA, Khalili D. 2012. Preparation of frost atlas using different interpolation methods in a semiarid region of south of Iran. Theoretical and Applied Climatology 108 (1-2): 159-171. DOI: 10.1007/s00704-011-0522-9

Diodato N. 2005. The influence of topographic co-variables on the spatial variability of precipitation over small regions of complex terrain. International Journal of Climatology 25: 351363. DOI: $10.1002 /$ joc. 1131

Güler M, Kara T. 2012. Geographic information system approaches for incorporating climatological parameters into the spatial interpolation of landbased areas: a general view. Journal of agricultural Faculty Ondokuz Mayls Universty 22(3): 322-328

Hudson G, Wackernagel H. 1994. Mapping Temperature Using Kriging with External Drift - Theory and an Example from Scotland. International Journal of Climatology 14(1): 77-91. DOI: 10.1002/joc.3370140107

Isaaks EH, Srivaslava RM. 1989. Applied Geostatistics. Oxford University Press: Oxford.Li J, Heap AD. 2008. A review of spatial interpolation methods for environmental scientists, 2008/23. Geoscience Australia

Li J, Heap AD. 2011. A review of comparative studies of spatial interpolation methods in environmental sciences: Performance and impact factors. Ecological Informatics 6(3-4): 228-241. DOI:10.1016/j.ecoinf.2010.12.003

Malvic T, Durekovic M. 2003. Application of methods: Inverse distance weighting, ordinary kriging and collocated cokriging in porosity evaluation, and comparison of results on the Benicanci and Stari Gradac fields in Croatia. Nafta, 54(9): 331-340

Moral FJ. 2010. Comparison of different geostatistical approaches to map climate variables: application to precipitation. International Journal of Climatology 30(4): 620-631. DOI: 10.1002/joc. 1913

Ünal MR. 2010. Kayisi araştirma raporu. Fırat Kalkınma Ajansı, Malatya

Vicente-Serrano SM, Saz-Sanchez MA, Cuadrat JM. 2003. Comparative analysis of interpolation methods in the middle Ebro Valley (Spain): application to annual precipitation and temperature. Climate Research 24(2): 161-180. DOI: $10.3354 / \mathrm{cr} 024161$

Webster, R. 2001. Statistics to support soil research and their presentation. European Journal of Soil Science 52(2): 331-340. DOI: $10.1046 / j .1365-2389.2001 .00383 . x$

Yang, JS, Wang, YQ, August, PV. 2004. Estimation of land surface temperature using spatial interpolation and satellitederived surface emissivity. Journal of Environmental Informatics 4(1): 37-44

Yates SR, , Warrick AW. 1987. Estimating Soil Water Content Using Cokriging. Soil Science Society of America Journal 51(1): 23-30. 